\title{
Family physicians' utility of social media: a survey comparison among family medicine residents and physicians
}

\author{
Karim Syed Irfan ${ }^{1}$, Irfan Farhana ${ }^{2}$, Al Faris Eiad ${ }^{2}$, Al Maflehi Nassr ${ }^{3}$, Al Qahtani Al Mohammed ${ }^{1}$, \\ Nadeem Maya ${ }^{4}$, Al Hazmi Ali ${ }^{1}$, Ahmed Abdullah MA², Ponnamperuma Gominda ${ }^{5}$, Vleuten Cees van der ${ }^{6}$
}

1. Department of Family and Community Medicine, College of Medicine, King Saud University, Riyadh, Saudi Arabia.

2. King Saud University Chair of Medical Education Research and Development, Department of Family and Community Medicine, College of Medicine, King Saud University, Riyadh, Saudi Arabia.

3. College of Dentistry, King Saud University, Riyadh, Saudi Arabia.

4. University College, University of Toronto, Ontario, Canada .

5. Centre for Medical Education, National University of Singapore, Singapore.

6. Deparmtent of Educational Development \& Research Maastricht University , Netherland.

\section{Author details:}

Karim Syed Irfan: Email: irfankarim1969@gmail.com; Irfan Farhana: Email: masoodfarhana1969@gmail.com; Al Faris Eiad: Email:efarisx2@gmail.com; Al Maflehi Nassr: Email: nassr@ksu.edu.sa; Al Qahtani Al Mohammed: Email : dr-manq@hotmail. com; Nadeem Maya: Email: mayanadeem94@gmail.com; Al Hazmi Ali:. Email: aalhazmii@ksu.edu.sa; Ahmed Abdullah MA: Email: shabalah_am@hotmail.com; Ponnamperuma Gominda: Email: gomindap@hotmail.com.

\begin{abstract}
:
Introduction: Social media has become ubiquitous and has brought a dramatic change in health services. Little is known about its use by family physicians and residents for personal or professional purpose. The aim of the current study was to evaluate the utility of social media among family medicine residents and consultants.

Methods: The collection of data was through the use of a five part questionnaire developed by researchers. The questionnaire was delivered to 70 physicians and 100 residents, out of which 132questionnaires were completed, representing a 78 percent response rate. Results: Our findings demonstrate that there was an overall high use of social media. Females used social media more for general education and professional purposes. Men, by contrast, used it more frequently for personal purposes. The participants in this study appeared to consider social media as having several useful dimensions, such as: enabling them to accomplish job tasks, improve job performance, productivity and more effective patient care when using social media.

Conclusions: To date, limited studies have compared social media use among family physicians and residents. This study may serve as an initial step for future studies explaining the pattern of use among physicians.

Keywords: social media, family physicians, learning, pattern of use, attitudes and gender differences.

DOI: https://dx.doi.org/10.4314/ahs.v18i3.41

Cite as: Irfan KS, Farhana I, Eiad AF, Nassr AM, Al Mohammed AQ, Maya N, Ali AH, Abmed Abdullah MA, Gominda P, Cees van der V. Family physicians' utility of social media: a survey comparison among family medicine residents and physicians. Afri Health Sci. 2018;18(3): 817-827. https://dx.doi.org/10.4314/abs.v18i3.41
\end{abstract}

\section{Corresponding author:}

Karim Syed Irfan,

Department of Family and Community

Medicine (34), College of Medicine,

King Saud University,

P.O.Box 2925, Riyadh 11461,

Kingdom of Saudi Arabia.

Phone number: +966114679253

Fax number: +966114671967

Email: irfankarim1969@gmail.com

\section{Introduction}

Social media use has grown substantially in the past decade $^{1}$. It has become an integral tool for physicians to solicit medical information ${ }^{2}$. Recent estimates of social media usage by doctors has risen dramatically from $41 \%$ in 2010 to $90 \%$ in $2011^{3}$. A major rationale for its widespread utilization is its ease of use $^{4}$.

According to uses and gratifications theory, media consumption is purposive and users search for relevant sites to fulfill their needs ${ }^{5}$.

A systematic review on social media use in medical edu-

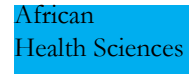

817
(C) 2018 Irfan et al. Licensee African Health Sciences. This is an Open Access article distributed under the terms of the Creative commons Attribution License (https://creativecommons.org/licenses/BY/4.0), which permits unrestricted use, distribution, and reproduction in any medium, provided the original work is properly cited.

African Health Sciences Vol 18 Issue 3, September, 2018 
cation using the nine databases (MEDLINE, CINAHL, ERIC, Embase, PsycINFO, ProQuest, Cochrane Library, Web of Science, and Scopus) conducted a literature search using the following defined terms: medical education, undergraduate medical education, graduate medical education, continuing medical education, medical student education, and resident education in combination with variations of the following "All Fields" terms: social media, social network, Facebook, Web 2.0, Web log, blog, Twitter, podcast, and Webcast from the start of each database till 2011 and found that interventions using social media tools are associated with improved knowledge, attitudes, and skills ${ }^{6}$. Social media channels are increasingly used as an educational source, and as powerful platforms to allow physicians to use and disseminate information ${ }^{7,8}$. As a universal information nidus, it provides a comprehensive database of answers. Its importance in clinical practice has been documented in the academic literature e,10,11,12. $^{2}$.

According to technology acceptance model (TAM) an individual's acceptance of technology is determined by its perceived utility (perceived usefulness, relevance, importance, timeliness, accessibility or ease of use of information or of a source. $)^{13}$. Perception and use may differ between various age cohorts ${ }^{14}$.

Younger doctors use social media more frequently than seniors, since juniors may have more familiarity with the technology and find it easy to use ${ }^{15}$.

When facing the broad range of patients' ailments, family physicians require a timely access to knowledge from trustworthy sources to help in clinical decisions. To comprehend this phenomenon amongst family physicians and residents, an understanding of how this group currently utilizes (perceived usefulness, relevance, importance, timeliness, accessibility or ease of use of information) social media is required.

There has been limited research on family physicians' utility of this technology or their attitudes towards $i t^{16,17}$. A literature search found limited studies comparing social media use between Family physicians and residents ${ }^{18}$.

Hence, this study aimed to:

1. Assess the pattern and extent of social media use, among residents and practicing family physicians, and association with the socio-demographic variables.
2. Identify the attitudes, the perceived usefulness, and barriers to its use.

\section{Methodology}

\section{Study design: Cross-sectional descriptive study.}

Study population: The study targeted the Family Physicians and Residents (from the joint program) at the King Saud University, Riyadh, Saudi Arabia during the year 2014-15. The residents were almost all Saudi (a homogenous set with similar ethnicity and cultural backgrounds). However, the physicians are a mix from different ethnic and cultural backgrounds.

\section{Data sampling method}

All the physicians and residents in the joint program were invited to participate.

Survey instrument development: A self-administered questionnaire was designed by the study team based on the existing literature ${ }^{19,20}$; the items were reviewed by a team of experts. Only those items which were relevant for our study, guided by research questions were included. The statements were ordered in a logical sequence so that the questionnaire would be easy to work through. The survey instrument examined four content areas: A) Basic characteristic of the study population; B) Usage of social media C) Frequency of Social Media Usage D) Attitudes toward Social Media Usage which covered areas such as Usefulness, ease of use and Barriers E) Types of social media use (Appendix 1).

The collected demographic dataincluded age, gender, marital status, highest degree and the type of practice. The survey instrument was piloted with ten residents and practicing physicians.

The reliability of the survey items was calculated for all questionnaire items. The alpha coefficient for our variables was 0.954 .

\section{Ethics approval:}

The current study was approved by the Institutional Review Board of the College of Medicine; King Saud University (reference \# E-14-1284). Participation was voluntary. Informed written consent was obtained from the participants and anonymity was assured. 


\section{Data collection}

The survey questionnaire was distributed and collected as a hard copy (manually) from all the participants. The first page of the questionnaire explained the aims of the study and assured of anonymity and confidentiality. Data collection lasted around two months. No incentives were offered for survey completion.

\section{Data analysis plan:}

The Statistical Package for the Social Sciences (SPSS) version 21 was used for data analysis. Descriptive statistics such as frequency, percentages, mean, and standard deviation were calculated. Comparisons were made between different categorical variables using Chi-square and other parametric tests as appropriate. A p value $<0.05$ was considered significant.

\section{Results}

The survey was delivered to 70 physicians and 100 residents. The total number who filled out the questionnaire was 132 . The overall response rate was $78 \%$. Out of 100 residents, 92 responded $92.0 \%$ and out of 40 physicians, $57 \%$ responded.

Men outnumbered women with a ratio of $(7 / 3)$. The mean age of the participants was $34.63+9.50$ years. Most of the physicians were younger than 40 years $(77.0 \%)$ and were married $(71.2 \%)$. (Table 1$)$.

\section{Table 1: Socio demographic characteristics of Family Physicians and residents}

\begin{tabular}{|c|c|}
\hline \multicolumn{2}{|c|}{ Demographics Characteristics } \\
\hline Participant Characteristics & $\begin{array}{l}\text { No (\%) of } \\
\text { respondents }\end{array}$ \\
\hline \multicolumn{2}{|c|}{ Age } \\
\hline Mean \pm SD & $34.63 \pm 9.50$ \\
\hline \multicolumn{2}{|l|}{ Age (years) } \\
\hline $20-30$ & $64(48.4)$ \\
\hline $31-40$ & $37(28.0)$ \\
\hline $41-50$ & $16(12.1)$ \\
\hline$\geq 50$ & $15(11.3)$ \\
\hline \multicolumn{2}{|c|}{ Gender } \\
\hline Male & $92(69.7)$ \\
\hline Female & $40(30.3)$ \\
\hline \multicolumn{2}{|c|}{ Marital Status } \\
\hline Married & $94(71.2)$ \\
\hline Single & $37(28.8)$ \\
\hline \multicolumn{2}{|c|}{ Type of Practice } \\
\hline Residents & $92(70)$ \\
\hline Physicians & $40(30.0)$ \\
\hline \multicolumn{2}{|c|}{ Highest Degree } \\
\hline MBBS & $79(59.8)$ \\
\hline Post graduate Qualification & $53(40.1)$ \\
\hline
\end{tabular}


Nearly all participants reported having social media accounts and reported checking them at least once a day (95.4\%); half of the participants (51\%) checked them four times or more daily (51\%). The median time spent on social media sites during a typical working day was 120 minutes with an interquartile range of 60-180 minutes.

Most of the participants (80\%) were happy with their social media usage (Table 2).

\section{Table 2: Gender and professional status differences of social media use by family physicians}

\begin{tabular}{|c|c|c|c|c|c|c|c|}
\hline $\begin{array}{l}\text { Item } \\
\text { description }\end{array}$ & $\begin{array}{l}\text { Total } \\
\mathbf{N} \\
(\%) \mathbf{N}=132\end{array}$ & $\begin{array}{l}\text { Male } \\
\mathrm{n}=92 \\
(\%)\end{array}$ & $\begin{array}{l}\text { Femalen }=40 \\
(\%)\end{array}$ & $\mathbf{P}$ value & $\mid \begin{array}{l}\text { Resident } \\
\mathrm{n}=92, \%\end{array}$ & \begin{tabular}{|l|} 
physician \\
$n=40, \%$
\end{tabular} & P value \\
\hline $\begin{array}{l}\text { Happy with } \\
\text { their social } \\
\text { media use? }\end{array}$ & $105(79.5)$ & 78.3 & 83 & 0.579 & 77.2 & 85 & 0.306 \\
\hline $\begin{array}{l}\text { Using social } \\
\text { media for } \\
\text { personal } \\
\text { purposes n } \\
(\%)\end{array}$ & $100(75.7)$ & 83.5 & 60.0 & 0.004 & 78.0 & 72.5 & 0.49 \\
\hline $\begin{array}{l}\text { Using social } \\
\text { media for } \\
\text { CME } \\
\text { purpose } \mathrm{n} \\
(\%)\end{array}$ & $24(18.1)$ & 17.6 & 20.0 & 0.458 & 15.4 & 25.0 & 0.19 \\
\hline $\begin{array}{l}\text { Using social } \\
\text { media for } \\
\text { general } \\
\text { education }\end{array}$ & $60(45.4)$ & 40.0 & 60.0 & 0.024 & 46.2 & 45.0 & 0.90 \\
\hline $\begin{array}{l}\text { Using social } \\
\text { media for } \\
\text { professional } \\
\text { purposes n } \\
(\%)\end{array}$ & $34(25.7)$ & 18.0 & 45.0 & 0.001 & 21.0 & 37.5 & 0.04 \\
\hline
\end{tabular}

Females showed statistically significant higher frequency of Google+ use for general use and for learning ( $\mathrm{p}=0.008$, 0.000) compared to their male counterparts (Table 4). However, men, reported a higher frequency of general purposes use of YouTube $(73.9 \%$ versus $55 \% ; \mathrm{p}=0.032)$, and Twitter (57.6\% versus $35.0 \%$; $\mathrm{p}=0.017)$.

Most of the study population used social media for personal purposes $(76.0 \%)$, general education $(46.0 \%)$, and professional reasons $(26.0 \%)$ and a smaller proportion for continuing medical education (18.2\%) (Table 2). A significantly higher proportion of male participants $(83.5 \%)$ utilized social media for personal use when compared to female physicians $(60 \%)(\mathrm{p}=0.004)$. On the other hand, female physicians had a statistically significant higher frequency for professional purposes (patient care) and for general education ( $\mathrm{p}=0.001, \mathrm{p}=0.02)$. Overall, physicians used social media significantly more (38\%) than residents $(21.0 \%)$ for professional purposes $(\mathrm{P}=0.04)$ (Table 2$)$.

The tools most frequently accessed were YouTube $(68.2$ $\%$ ), Facebook (45.5\%), and Wikipedia (37.9 \%). LinkedIn $(14.4 \% \%)$ was the least favorite social media application. A statistically significant higher proportion of physicians used Facebook in general as compared with residents $(\mathrm{p}=0.027)$. Regarding other sites, no significant differences were observed. (Table 3). 
Table 3: Association of gender and professional status with social media usage among family physicians

\begin{tabular}{|c|c|c|c|c|c|c|c|}
\hline & & $\begin{array}{l}\text { Male } \\
n=92(\%)\end{array}$ & $\begin{array}{l}\text { Female } \\
n=40(\%)\end{array}$ & P value & $\begin{array}{l}\text { Resident } \\
\mathrm{n}=92(\%)\end{array}$ & $\begin{array}{l}\text { Physician } \\
n=40(\%)\end{array}$ & $\begin{array}{l}\mathrm{P} \\
\text { value }\end{array}$ \\
\hline \multirow{9}{*}{1} & & & & & & & \\
\hline & For general purposes & & & & & & \\
\hline & You'Tube & $68(73.9)$ & $22(55.0)$ & 0.032 & $64(69.6)$ & $26(65.0)$ & 0.605 \\
\hline & Facebook & $44(47.8)$ & $16(40.0)$ & 0.407 & $36(39.1)$ & $24(60.0)$ & 0.027 \\
\hline & twitter & $53(57.6)$ & $14(35.0)$ & 0.017 & $51(55.4)$ & $16(40.0)$ & 0.103 \\
\hline & LinkedIn & $12(13.2)$ & $7(17.5)$ & 0.519 & $11(12.1)$ & $8(20.0)$ & 0.236 \\
\hline & Wikipedia & $38(41.3)$ & $12(30.0)$ & 0.219 & $36(39.1)$ & $14(35.0)$ & 0.653 \\
\hline & Google+ & $26(28.3)$ & $21(52.5)$ & 0.008 & $34(37.0)$ & $13(32.5)$ & 0.623 \\
\hline & Instagram & $26(28.3)$ & $15(37.5)$ & 0.292 & $32(34.8)$ & $9(22.5)$ & 0.161 \\
\hline \multirow[t]{8}{*}{2} & $\begin{array}{l}\text { For learning } \\
\text { purposes }\end{array}$ & & & & & & \\
\hline & YouTube & $60(65.2)$ & $24(60.0)$ & 0.567 & $62(67.4)$ & $22(55.0)$ & 0.174 \\
\hline & Facebook & $23(25.0)$ & $10(25.0)$ & 1.000 & $21(22.8)$ & $12(30.0)$ & 0.382 \\
\hline & twitter & $27(29.3)$ & $9(22.5)$ & 0.417 & $22(23.9)$ & $14(35.0)$ & 0.189 \\
\hline & LinkedIn & $4(4.3)$ & $5(12.5)$ & 0.088 & $5(5.4)$ & $4(10.0)$ & 0.339 \\
\hline & Wikipedia & $46(50.0)$ & $16(40.0)$ & 0.290 & $45(48.9)$ & $17(42.8)$ & 0.497 \\
\hline & Google+ & $20(21.7)$ & $31(77.5)$ & 0.000 & $36(39.1)$ & $15(37.5)$ & 0.860 \\
\hline & Instagram & $7(7.6)$ & $7(17.5)$ & 0.090 & $11(12.0)$ & $3(7.5)$ & 0.0445 \\
\hline 3 & $\begin{array}{l}\text { Do you think you are } \\
\text { addicted to social } \\
\text { media (yes) }\end{array}$ & $29(32.0)$ & $12(30.0)$ & 0.832 & $33(35.0)$ & $8(20.5)$ & 0.083 \\
\hline
\end{tabular}

In comparing the significance of the internetto other sources of accessing clinical information, participants favored the internet $(78 \%)$, followed by books $(65.2 \%)$, and, finally colleagues $(39 \%)$. Less preferred sources were conferences $(37 \%)$, scientific journals $(32 \%)$, and pharmaceutical representatives $(10 \%)$.

Overall, on a daily basis, $33 \%$ of respondents used social media to explore medical information and $23.4 \%$ to contribute information to others. Once a week or more, the corresponding figures were $39 \%$ and $33 \%$.

Female participants admitted that they would contribute information to others $(\mathrm{p}=0.029)$, seek specific information $(\mathrm{p}=0.005)$, and explore medical knowledge $(\mathrm{p}=0.041)$ as compared to their male counterparts (Table 4). Residents were more likely to be actively seeking information as compared to physicians, specifically about a medical problem or situation. $(\mathrm{p}=0.055)$. 
Table 4: Association of gender and professional status with the frequency of social media usage to fulfill information needs of family physicians

\begin{tabular}{|c|c|c|c|c|c|c|c|}
\hline & & $\begin{array}{l}\text { Male } \\
\mathrm{n}=92 \\
(\%)\end{array}$ & $\begin{array}{l}\text { Female } \\
\mathrm{n}=40 \\
(\%)\end{array}$ & P value & $\begin{array}{l}\text { Resident } \\
\mathrm{n}=62 \\
(\%)\end{array}$ & $\begin{array}{l}\text { Physician } \\
\mathrm{n}=22(\%)\end{array}$ & $\mathbf{P}$ \\
\hline 1 & \multicolumn{7}{|c|}{ Frequency of social media use to contribute knowledge to others } \\
\hline & Never & $19(20.9)$ & $8(20.0)$ & \multirow{6}{*}{0.029} & $20(21.7)$ & $7(17.9)$ & \multirow{6}{*}{0.355} \\
\hline & Monthly & $25(27.5)$ & $5(12.5)$ & & $17(18.5)$ & $13(33.3)$ & \\
\hline & Once a week & $16(17.6)$ & $6(15.0)$ & & $15(16.3)$ & $7(17.9)$ & \\
\hline & 2-4 times/week & $15(16.5)$ & $6(15.0)$ & & $16(17.4)$ & $5(12.8)$ & \\
\hline & Daily & $10(11.0)$ & $13(32.5)$ & & $16(17.39)$ & $7(17.5)$ & \\
\hline & Many times a day & $6(6.6)$ & $2(5.0)$ & & $8(8.7)$ & $0(0.0)$ & \\
\hline 2 & \multicolumn{7}{|c|}{$\begin{array}{c}\text { Frequency of social media use to seek specific information about a medical } \\
\text { problem }\end{array}$} \\
\hline & Never & $18(19.8)$ & $1(2.5)$ & \multirow{6}{*}{0.005} & $12(13.0)$ & $7(17.9)$ & \multirow{6}{*}{0.503} \\
\hline & Monthly & $15(16.5)$ & $3(7.5)$ & & $10(10.9)$ & $8(20.5)$ & \\
\hline & Once a week & $16(17.6)$ & $8(20.0)$ & & $16(17.4)$ & $8(20.5)$ & \\
\hline & 2-4 times/week & $19(20.9)$ & $8(20.0)$ & & $19(20.7)$ & $8(20.5)$ & \\
\hline & Daily & $13(14.1)$ & $15(37.5)$ & & $22(23.9)$ & $6(15.0)$ & \\
\hline & Many times a day & $10(11.0)$ & $5(12.5)$ & & $13(14.1)$ & $2(5.1)$ & \\
\hline 3 & \multicolumn{7}{|c|}{$\begin{array}{l}\text { Frequency of social media use to explore medical knowledge for new } \\
\text { insights }\end{array}$} \\
\hline & Never & $21(22.8)$ & $2(5.1)$ & \multirow{6}{*}{0.041} & $16(17.4)$ & $7(17.9)$ & \multirow{6}{*}{0.055} \\
\hline & Monthly & $14(15.2)$ & $4(10.3)$ & & $11(12.0)$ & $7(17.9)$ & \\
\hline & Once a week & $22(23.9)$ & $9(23.1)$ & & $23(25.0)$ & $8(20.5)$ & \\
\hline & 2-4 times/week & $17(18.5)$ & $8(20.5)$ & & $14(15.2)$ & $11(28.2)$ & \\
\hline & Daily & $9(9.7)$ & $11(27.5)$ & & $15(16.30)$ & $5(12.5)$ & \\
\hline & Many times a day & $9(9.8)$ & $5(12.8)$ & & $13(14.1)$ & $1(2.6)$ & \\
\hline
\end{tabular}

Regarding the participants attitude towards social media use; approximately one-third of respondents considered them an essential use of time (65.9\%), beneficial ( $77.3 \%)$, very engaging $(72.0 \%)$ and a great way to get high-quality current information (76.3\%) (Figure 1).
Approximately, more than $80 \%$ of physicians felt it was easy to use social media, and $65 \%$ believed that social media increased their job performance and improved the quality of patients' care $(62 \%)$. As expected, barriers identified were time constraint $(50 \%)$ and skills for use of social media $(66 \%)$. 


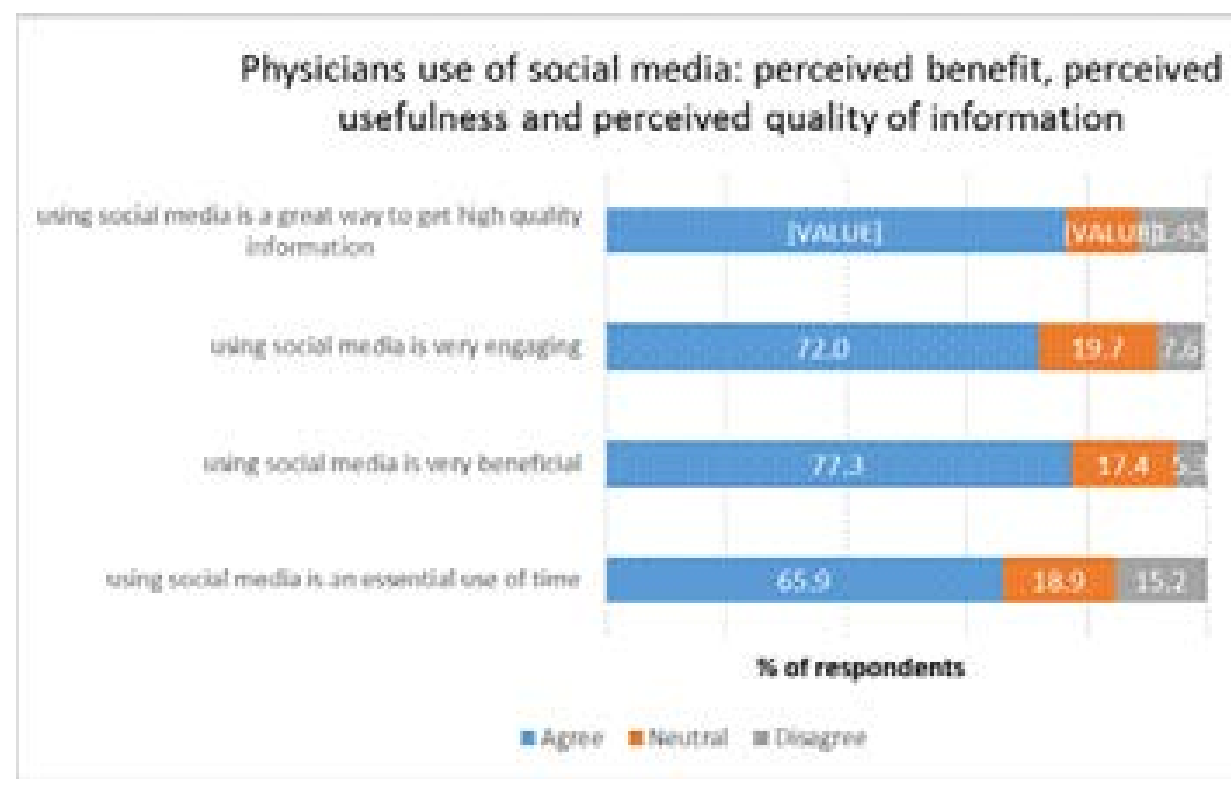

\section{Figure 1: Physicians perception of the benefit, usefulness and quality of information of social media:}

\section{Discussion}

Our findings demonstrate that there was an overall high use of social media among family medicine residents and practitioners of both sexes. Generally, females used social media more for general education and professional purposes. Men, by contrast, used it more frequently for personal purposes.

The most common types of social media used by participants were YouTube, Facebook and Wikipedia. Physicians considered social media to be beneficial and preferred social media over traditional approaches such as conferences and scientific journals for learning. They also thought it a great way to get high quality information, found it to be very engaging, and an effective use of time. Lately, the use of social media by health care professionals has increased significantly ${ }^{21}$. The higher use of social media in our study is consistent with previous literature that have shown that more than $90 \%$ of the physicians are social network users ${ }^{18}$. The use of social networking sites among youth and adults alike has risen significantly, however there are difference in trends of use amongst various age cohorts. We found a "digital divide" between physicians and residents in terms of using the social media. Residents were more likely to use social media than the physicians, although it was not significant. This is in keeping with other studies reporting young age as a pre- dictor of social network users ${ }^{6,22,23,24}$. The rate at which social media use is diffusing among the older generation is escalating, and the digital immigrants 16 are striving to close the gap by adopting social media habits similar to digital natives; still, it lags behind the figures of the young users $^{25}$. A plausible explanation could be that for young doctors, social media has been an integral part of their life and they feel perfectly comfortable with it. In contrast, older physicians got a taste of this new technology at a later stage in their lives. As a result, comfort level and fluency may vary. Moreover, another possible explanation for our results, which issubstantiated by evidence, ${ }^{24,26}$ is that physicians, being more medically experienced, might feel less need for professional use compared to younger residents.

Historically, women have been more avid users of social media than men, but these differences are no longer statistically significant ${ }^{27}$. This is in line with our study finding. A variety of covariates are found to be associated with its use, but little systematic research has actually explored the reasons for these differences. An explanation for these differences seems like an important question, yet to be answered.

In general, adults as a whole remain less likely than the younger generation to use the technology $\mathrm{y}^{28}$, and the number further goes down with increasing age ${ }^{29}$.

African Health Sciences Vol 18 Issue 3, September, 2018 
Family Physicians used social media more for personal, than for professional or educational purposes. This result is in line with the findings of other studies among health care professionals ${ }^{19,30}$. A study among US physicians reported that $90 \%$ of physicians used social media for personal purposes and $65 \%$ for professional purposes ${ }^{22}$. However, for exploration of medical knowledge, physicians reported higher frequency of use as compared to residents. One of the reasons could be that the seniors emphasize the informational and educational aspects of the internet, while their younger counterparts use it for entertainment. As a result, its use can vary greatly among a cohort of doctors within the same institute. The digital immigrants are however trying to adopt social media habits similar to digital natives ${ }^{22}$. These results are exploratory and need further validation with larger scale studies using other physicians as well.

Men and women have varying degrees of activity across different social media sites. Not much is known about the factors that might influence the actual use of social media for personal purposes. Our findings show the male gender to be positively associated with personal social media use. These are comparable to those shown in other studies $^{24,31}$. A possible reason could be a higher use of internet by males in this region ${ }^{32}$. This issue deserves attention in future studies, since it might be associated with cultural differences.

Our study provides insight into family physicians' relationship with social media by investigating which source of information physicians and residents use for general and learning purposes. YouTube in this study was ranked the number one site for general and learning purposes. This finding contrasts a previous study on clinician use of social media that reported the use of Facebook ${ }^{33}$ and Wikipedia as high ${ }^{21}$. However, in a longitudinal study from 2009 to 2011, the use of social media increased tremendously, especially in the use of YouTube (from 2\% to $20 \%)^{34}$.

A plausible explanation could be that YouTube videos are search engine friendly and are easily accessible from both desktop and mobile devices, and healthcare professionals might come across them while doing Web searches. We suggest that future studies on this topic should include usage metrics, such as the amount and type of content

African Health Sciences Vol 18 Issue 3, September, 2018 consumed, and the number of connections made for better understanding of web usage.

A higher proportion of respondents in our study as well as in other studies ${ }^{22}$ were interested in updates through medically related social media sites

The participants in this study appeared to consider social media as having several useful dimensions such as: enabling them to accomplish job tasks, improve job performance, productivity, and more effective patient care. Their attitudes towards its use were also positive, and the majority thought social media to be engaging, beneficial, and an effective use of time. Nonetheless, participants also identified several barriers, which were similar to previous research ${ }^{22}$ findings. The barriers hindering the use of social media were a busy schedule, and investment of time and skill.. A highly possible explanation could be the time investment, as most doctors are usually pressed for time, trying to balance work and life ${ }^{35}$.

\section{Limitations:}

Several limitations of the current study must be noted. First, the current study was conducted on a relatively small number of residents and physicians who were from the same region, which may not be a representative group of full network of physicians on social media. This reduces the generalizability of the findings.

Second, the questionnaire was pilot tested, but not validated. Additionally, social media usage and barriers were measured using only few items, which limits our ability to generalize to a wide variety of issues. To address this, future in depth studies should attempt to explore the issue by using more comprehensive measures. Thirdly, social media usage and attitudes are changing at a fast pace, and they might have changed over this period. Finally, the results of this study need to be supplemented with qualitative study to better understand this phenomenon.

The gender differences found in the use of social media for professional purposes in this study may have impact on how the different genders approach patient care. Although physician sex doesnot determine patient outcomes, it can serve as a sign of difference in practice. However, these attributes may change as the technologies evolve and will require further observation over time.

Despite limitations, the study may serve as an initial step for future studies explaining the pattern of use in different cultures. 


\section{Conclusion}

This study demonstrates that social media was very popular among physicians and residents. YouTube emerged as the most frequently used application. Females and physicians used social media more for professional purposes than did residents. Male physicians used social media less for educational and learning purposes, and instead used it for personal reasons and leisure. Majority found it to be an effective use of time, and a beneficial and engaging way to get high-quality information. Further research is required to evaluate this difference to verify whether it is culture or career specific.

\section{Declarations}

\section{Ethics approval and consent to participate:}

Informed written consent was obtained from all participants prior to data collection. All the selected respondents were given assurance of confidentiality that the information gathered will be used exclusively for research purposes. The current study was approved by the Institutional Review Board of the College of Medicine; King Saud University (reference no E-14-1284).

\section{Consent for publication: Not applicable.}

Financial Support: This work was supported by the Deanship of Scientific Research, King Saud University for funding through Vice Deanship of Scientific Research Chairs.

Availability of data and materials: The datasets used during the current study are available from the corresponding author on request.

Competing interests: The authors declare that they have no competing interests.

\section{Authors' contributions}

IK contributed to the study conception and design. FI contributed to the initial draft and revision of the subsequent drafts of the manuscript and analyses of results. EA, GP AA, MQ, AH, MN were involved in revision of the subsequent drafts of the manuscript. NM did the statistical analysis. CV contributed to critical revision of manuscript. All authors read and approved the final version of the manuscript.

\section{Acknowledgment}

We gratefully acknowledge the residents and physicians who participated in this study and the administration who helped collect data for this study.

\section{References}

1. The Nielsen Company. Global Faces and Networked Places; The Nielsen Company: New York, NY, USA, 2009; Available online: http://blog.nielsen.com/nielsenwire/wp-content/uploads/2009/03/nielsen_globalfaces_mar09.pdf. Accessed 4 March 2017

2. Vollmar HC, Rieger MA, Butzlaff ME, Ostermann T. General Practitioners' preferences and use of educational media: a German perspective. BMC Health Serv Res. 2009; 9:31. PubMed doi: 10.1186/1472-6963-9-31.

3. George DR, Rovniak LS, Kraschnewski JL. Dangers and opportunities for social media in medicine. Clin Obstet Gynecol. 2013 Sep;56(3):453-62. doi: 10.1097/ GRF.0b013e318297dc38.

4. J Sandars, S Schroter. Web 2.0 technologies for undergraduate and postgraduate medical education: an online survey. Postgrad Med J. 2007;83:759- PubMed ;762. doi: 10.1136/pgmj.2007.063123

5. Zohoorian-Fooladi N, Abrizah. Exploration of uses and gratification of social media application among academic librarians in Malaysia: a preliminary study ICOLIS 2012, Kuala Lumpur: LIS, FCSIT, 2012: pp 165-176 available from http://repository.um.edu.my/26302/1/2_16\%20 Niusha $\% 20$ Abrizah $\% 20$ Exploration $\% 20$ of $\% 20$ uses $\% 20$ and $\% 20$ gratification $\% 20$ of $\% 20$ social $\% 20$ media $\% 20$ NHA $\% 20$ edited.pdf

6. Cheston CC, Flickinger TE, Chisolm MS. Social media use in medical education: a systematic review. Acad Med. 2013 Jun; 88(6):893-901.

7. Cooper CP, Gelb CA, Rim SH, Hawkins NA, Rodriguez JL, Lindsey Polonec. Physicians Who Use Social Media and Other Internet-based Communication Technologies. J Am Med Inform Assoc. 2012;19(6):960 PubMed -964. Available from: http://www.medscape.com/viewarticle/772791.

8. Grajales III FJ, Sheps S, Ho K, Novak-Lauscher H, Eysenbach G Social Media: A Review and Tutorial of Applications in Medicine and Health Care. J Med Internet Res. 2014;16(2): PubMed e13. DOI: 10.2196/jmir.2912

9. Bennett NL, Casebeer LL, Kristofco R, Collins BC. Family physicians' information seeking behaviors: a sur- 
vey comparison with other specialties. BMC Med Inform Decis Mak. 2005;5(1):9.

10. Ebell MH, Frame P. What can technology do to, and for, family medicine? Family Medicine. 2001, 33 (4): 311 PubMed -9.

11. Eitel DR, Yankowitz J, Ely JW. Use of Internet Technology by Obstetricians and Family Physicians. JAMA. 1998, 280 (15): 1306 PubMed -1307. doi.10.1001/ jama.280.15.1306.

12. Casebeer L, Bennett N, Kristofco R, Carillo A, Centor R. Physician Internet medical information seeking and on-line continuing education use patterns. J Contin Educ Health Prof. 2002, 22 (1): 33-42.

13. Davis FD. Perceived usefulness, perceived ease of use, and user acceptance of information technology. Manag Inf Syst Q. 1989;13:319-340 PubMed .

14. J. Brown, C. Ryan, A. Harris. How Doctors View and Use Social Media: A National Survey. J Med Internet Res. 2014 Dec; 16(12): e267

15. Moubarak G, Guiot A, Benhamou Y, Benhamou A, Hariri S. Facebook activity of residents and fellows and its impact on the doctor-patient relationship. J Med Ethics. 2011 Feb;37(2):101-104

16. Gholami-Kordkheili F, Wild V, Strech D. The impact of social media on medical professionalisocial media: a systematic qualitative review of challenges and opportunities. J Med Internet Res. 2013;15 (8): PubMed e184

17. Usher WT. Australian health professionals' social media (Web 2.0) adoption trends: early 21st century health care delivery and practice promotion. Aust J Prim Health. 2012;18(1):31 PubMed -41.

18. Klee D, Covey C, Zhong L Social media beliefs and usage among family medicine residents and practicing family physicians. Fam Med. 2015 Mar;47(3):222-6.

19. Wang AT, Sandhu NP, Wittich CM, Mandrekar JN, Beckman TJ. Using social media to improve continuing medical education: a survey of course participants. Mayo Clin Proc. 2012 Dec;87(12):1162-70.

20. McGowan BS, Wasko M, Vartabedian BS, Miller RS, Freiherr DD, Abdolrasulnia M.Understanding the factors that influence the adoption and meaningful use of social media by physicians to share medical information. $J$ Med Internet Res. 2012 Sep 24;14(5):e117.

21. M. Von Muhlen, L. Ohno-Machado. Reviewing social media use by clinicians. J Am Med Inform Assoc, 19 (2012), pp. 777-781.

22. Adilman R, Rajmohan Y, Brooks E, Urgoiti GR,
Chung C, Hammad N, Trinkaus M1, Naseem M, Simmons C, Adilman R, Rajmohan Y, Brooks E, Roldan Urgoiti G, Chung C, Hammad N, Trinkaus M, Naseem M, Simmons C.Social Media Use Among Physicians and Trainees: Results of a National Medical Oncology Physician Survey. J Oncol Pract. 2016 Jan;12(1):79-80, e52-60. doi: 10.1200/JOP.2015.006429. Epub 2015 Oct 6.

23. Perrin A. 2015. Social media Usage: 2005-2015. Numbers, facts and trends shaping the world. Pew Research Center. cited 2016 May 12. Available from: http:/ / www.pewinternet.org/2015/10/08/2015/Social-Networking-Usage-2005-2015/ (accessed on 12 May 2016).

24. Garritty C, El Emam K Who's Using PDAs? Estimates of PDA Use by Health Care Providers: A Systematic Review of Surveys. J Med Internet Res. 2006;8(2): PubMed e7. DOI: 10.2196/jmir.8.2.e7.

25. G. Paul, C. Stegbauer. Is the digital divide between young and elderly people increasing? First Monday, 2005. <http:/ / firstmonday.org/ojs/index.php/fm/article/ view/1286/1206. accessed 28 March 2017.

26. Romano M, Gesualdo F, Pandolfi E, Tozzi AE, Ugazio AG. Use of internet by Italian pediatricians : habits, impact on clinical practice and expectations. BMC Med Inform Decis Mak. 2012 Mar 28;12:23. doi: 10.1186/14726947-12-23.

27. Social Media Gender Gap Narrows. http://www. pewresearch.org/fact-tank/2015/08/28/men-catch-upwith-women-on-overall-social-media-use/ft_15-08-20_ socmedgender_narrows/. Accessed 19 April 2017.

28. Lenhart A, Purcell K, Social mediaith A, Zickuhr K. Social Media \& Mobile Internet Use among Teens and Young Adults. Millennials. Pew Internet \& American Life Project. https://eric.ed.gov/?id=ED525056. Accessed 20 April 2017.

29. Internet Usage in the Kingdom of Saudi Arabia. Integrated (All sectors), Communications and Information Technology Commission. The (2007) Report. http://www.citc.gov.sa/en/reportsandstudies/studies/ Documents $/ \mathrm{IT} \% 20015 \% 20 \mathrm{E} \% 20-\% 20$ Internet_Usage_ Study_in_KSAAll_sectors.pdf. Accessed 22 April 2017. 30. Sandars J, Schroter S. Web 2.0 technologies for undergraduate and postgraduate medical education: an online survey. Postgrad Med J. 2007; 83(986):759 PubMed -762. 31. R.K. Garrett, J.N. Danziger. Disaffection or expected outcomes: Understanding personal Internet use during work. J Comput Mediat Commun. , 13 (2008), pp. 937-958 32. Simsin MT, Internet usage and user preferences in 
Saudi Arabia Journal of King Saud University - Engineering Sciences. Volume 23, Issue 2, June 2011, Pages 101-107 http://doi.org/10.1016/j.jksues.2011.03.006

33. Modahl M, Doctors, Patients \& Social Media. http:// www.quantiamd.com/q-qcp/social_media.pdf .Accessed 22 April 2017.

34. Van de Belt TH, Berben SA, Samsom M, Engelen LJ,
Schoonhoven L. Use of social media by Western European hospitals: longitudinal study. J Med Internet Res. 2012 1;14(3 PubMed ):e61. doi: 10.2196/jmir.1992

35. Campbell L, Evans Y, Pumper M, Moreno MA. Social media use by physicians: a qualitative study of the new frontier of medicine. BMC Med Inform Decis Mak. 2016 Jul 15;16:91. doi: 10.1186/s12911-016-0327-y. 